\title{
Genetic Diversity and Mating Type Distribution of Pseudocercospora fijiensis on Banana in Uganda and Tanzania
}

\author{
Janet N. Kimunye, ${ }^{1,2}$ Norman Muzhinji, ${ }^{3}$ Diane Mostert, ${ }^{2}$ Altus Viljoen, ${ }^{2}$ Aletta E. Bester-van der Merwe, ${ }^{4}$ and \\ George Mahuku1,5,† \\ ${ }^{1}$ International Institute of Tropical Agriculture, P.O. Box 7878, Kampala, Uganda \\ ${ }^{2}$ Department of Plant Pathology, Private Bag X1, Stellenbosch University, Matieland 7602, South Africa \\ ${ }^{3}$ Department of Applied and Natural Sciences, Namibia University of Science and Technology, Private Bag 13388, Windhoek, Namibia \\ ${ }^{4}$ Department of Genetics, Private Bag X1, Stellenbosch University, Matieland 7602, South Africa \\ 5 International Institute of Tropical Agriculture, P.O. Box, 34441, Dar es Salaam, Tanzania \\ Accepted for publication 14 September 2020.
}

\begin{abstract}
Black Sigatoka, caused by Pseudocercospora fijiensis, is a major foliar disease of banana and plantain worldwide. There are few available data regarding the genetic diversity and population structure of the pathogen in East Africa, which are needed to design effective and durable disease management strategies. We genotyped 319 single-spore isolates of $P$. fijiensis collected from seven regions in Uganda and Tanzania and five isolates from Nigeria using 16 simple sequence repeat markers and mating type-specific primers. Isolates from each country and region within the country were treated as populations and subpopulations, respectively. A total of 296 multilocus genotypes (MLGs) were recovered, representing a clonal fraction of 7\%. Subpopulations had a moderate level of genetic diversity $\left(\mathrm{H}_{\exp }=0.12\right.$ to 0.31 ; mean, 0.29$)$. Mating type distribution did not deviate from equilibrium (MAT1-1: MAT1-2, 1:1 ratio) in Uganda; however, in Tanzania the mating types
\end{abstract}

ABSTRACT

Banana (Musa spp.) is a major staple and cash crop for many communities in the Great Lakes region of Africa. In Eastern Africa, the per capita consumption ranges between 250 and $400 \mathrm{~kg}$ annually (Karamura et al. 2012). Despite the importance of banana for food security and income generation, its production is constrained by many pests and pathogens, of which Pseudocercospora fijiensis (M. Morelet) Deighton, 1976, which is the causal agent of black Sigatoka, is one of the most destructive (Churchill 2011; Marin et al. 2003). On susceptible cultivars and under conducive environmental conditions, the disease rapidly defoliates banana, leading to yield losses between 20 and 50\% (Carlier et al. 2000; Mobambo et al. 1993).

Pseudocercospora fijiensis is a haploid, heterothallic, ascomycete fungus that reproduces sexually and asexually (Carlier et al. 2000; Churchill 2011). The asexual cycle produces conidia that are dispersed by rain splash and dew over short distances. The sexual cycle produces ascospores that are dispersed by wind over longer distances (Carlier et al. 2000). Long-distance dispersal and intercontinental spread of the pathogen occur through the movement of infected plant material (Carlier et al. 2000). The polycyclic nature of black Sigatoka provides the

†Corresponding author: G. Mahuku; G.Mahuku@cgiar.org

Funding: Support was provided by Bill and Melinda Gates Foundation (OPP1093845)

*The $\boldsymbol{e}$-Xtra logo stands for "electronic extra" and indicates there are supplementary materials published online.

The author(s) declare no conflict of interest.

Copyright (C) 2021 The Author(s). This is an open access article distributed under the CC BY 4.0 International license. were not in equilibrium (4:1 ratio). The index of association tests $\left(I_{A}\right.$ and $\left.\bar{r}_{d}\right)$ showed that all populations were at linkage equilibrium $(P>0.05)$, thus supporting the hypothesis of random association of alleles. These findings are consistent with a pathogen that reproduces both clonally and sexually. Low and insignificant levels of population differentiation were detected, with $90 \%$ of the variation occurring among isolates within subpopulations. The high intrapopulation variation has implications in breeding for resistance to $P$. fijiensis because isolates differing in aggressiveness and virulence are likely to exist over small spatial scales. Diverse isolates will be required for resistance screening to ensure selection of banana cultivars with durable resistance to Sigatoka in East Africa.

Keywords: Banana, black Sigatoka, East Africa, genotypic diversity, microsatellites

basis for rapid inoculum build-up and consequent epidemic development within a single growing season (Churchill 2011).

In Africa, P. fijiensis was first reported in Gabon, West-Central Africa, in 1978 (Frossard 1980). A second introduction was reported to have occurred a decade later in East Africa through the island of Pemba in Tanzania (Dabek and Waller 1990; Pasberg-Gauhl et al. 2000). However, population genetic studies did not confirm a double introduction; instead, they supported the hypothesis of a single introduction in Africa. The report did not specify the exact point of introduction (Robert et al. 2012). Black Sigatoka is now endemic within the African Great Lakes region, including the high-altitude banana-growing areas where the pathogen was previously absent (Erima et al. 2017; Kimunye et al. 2020). At commercial plantations where bananas are cultivated as a monoculture, P. fijiensis is managed using fungicides (Marin et al. 2003). However, fungicides are neither practical nor viable for economically constrained smallholder farmers (Alakonya et al. 2018). Furthermore, fungicides are a hazard to the environment and human health (Churchill 2011; de Bellaire et al. 2010), and their effectiveness over time is limited by the emergence of fungicide-resistant strains (de Bellaire et al. 2010).

The use of disease-resistant banana varieties is an integral part of sustainable and long-term management strategies for black Sigatoka (Carlier et al. 2000; Marin et al. 2003). However, developing Sigatoka-resistant bananas varieties is challenging because of different ploidy levels, parthenocarpy, and sterility (Tenkouano et al. 2011). This is compounded by a limited understanding of the genetic diversity, population structure, and evolutionary potential of $P$. fijiensis in East Africa. Such information is crucial for identifying suitable sources of resistance and for selecting pathogens with different virulence levels for use in screening for resistance in banana breeding programs. 
Diversity in populations of $P$. fijiensis is influenced by gene flow and levels of recombination that generate new combinations of alleles (Milgroom 1996). The heterothallic nature of P. fijiensis facilitates higher recombination frequency, which is important for generating and maintaining genetic diversity within the pathogen population (Irish et al. 2013; Mouliom-Pefoura 1999). New combinations of alleles increase the potential for the emergence of new genotypes capable of adapting to new environments, overcoming resistance in newly deployed cultivars, and adapting to novel fungicides (McDonald 1997; McDonald and Linde 2002; Milgroom 2015).

Sexual reproduction of $P$. fijiensis is controlled by the pairing of opposite mating-type (MAT) genes (Turgeon and Yoder 2000). The MAT1-1 and MAT1-2 genes are controlled by unrelated gene sequences, known as idiomorphs, which occur at the same chromosome region (Turgeon and Yoder 2000). The hypothesis that $P$. fijiensis undergoes regular cycles of sexual reproduction may be tested by analyzing the frequencies and distributions of matingtype idiomorphs (Milgroom 1996). An equal (1:1) frequency of mating types indicates random and frequent mating (Conde-Ferraez et al. 2010; Queiroz et al. 2013), which allows for the development of new recombinants and can support high genetic diversity in a pathogen population.

Knowledge of the distribution and genetic diversity of $P$. fijiensis is important for making inferences regarding the pathogen origin, sources of inoculum, routes of introduction, migration pathways, and modes of reproduction (Grünwald et al. 2017). Different molecular marker types, including restriction fragment length polymorphisms (RFLPs) (Carlier et al. 1996; Hayden et al. 2003), polymerase chain reaction RFLPs (PCR-RFLPs) (Rivas et al. 2004), variable numbers of tandem repeats (VNTRs) (Garcia et al. 2010), single nucleotide polymorphisms (SNPs) (Zandjanakou-Tachin et al. 2009), and simple sequence repeats (SSRs; also known as microsatellites) (Robert et al. 2012; Zapater et al. 2008) have been used to assess the genetic diversity of $P$. fijiensis. SSRs are particularly useful for population diversity and genetics studies because they are highly informative, co-dominant, and easy to genotype (Halkett et al. 2005; Karaoglu et al. 2005). The development and use of $P$. fijiensis-specific SSR markers have enabled the assessment of genetic diversity and spread of the pathogen at different spatial scales (Neu et al. 1999; Robert et al. 2010; Robert et al. 2012; Zapater et al. 2008).

Apart from a few previous studies of $P$. fijiensis populations from Uganda (Fahleson et al. 2009), little is known about the genetic diversity and population structure of $P$. fijiensis in East Africa. Information regarding evolutionary and dispersal potential, gene flow, and mating type distribution of $P$. fijiensis in East Africa may be helpful to those designing effective and durable disease management strategies for the region. We hypothesized that P. fijiensis populations in the region are sexual, genetically diverse, and geographically differentiated. To test these hypotheses, we assessed the genetic diversity of $P$. fijiensis populations from Uganda and Tanzania, determined interpopulation and intrapopulation differentiation and population structures, and deciphered the prevalent mode of reproduction based on the characteristics of the population genetics.

\section{MATERIALS AND METHODS}

Collection and isolation of $\boldsymbol{P}$. fijiensis. Banana leaves with symptoms of black Sigatoka were collected from seven bananagrowing regions in Tanzania and Uganda, either from farmer fields or from plots at agriculture research stations, between 2016 and 2018 (Fig. 1; Supplementary Table S1). In Tanzania, samples were collected from the Arusha-Tengeru Horticulture Research Farm, Agricultural Research Institute (ARI), and banana evaluation plots and farmer fields in the Mbeya and Kagera regions. In Uganda, samples were collected from Wakiso at the Kawanda National Agricultural Research Organization (NARO) banana breeding farm, Sendusu at the International Institute of Tropical Agriculture (IITA) banana breeding farm, and farmer fields in Mbarara and Luwero. In each of the seven regions, samples were randomly collected from farms that were at least 5 to $10 \mathrm{~km}$ apart. At farms, a leaf piece bearing mature (stage 6) (Foure 1987) black Sigatoka lesions was sampled from each of 15 plants. The leaf pieces were placed between newspaper sheets, pressed, and transported to the Plant Pathology Laboratory at IITA, Kawanda, in Uganda, or to the Plant Pathology Laboratory at IITA, Dar es Salaam, in Tanzania.
A

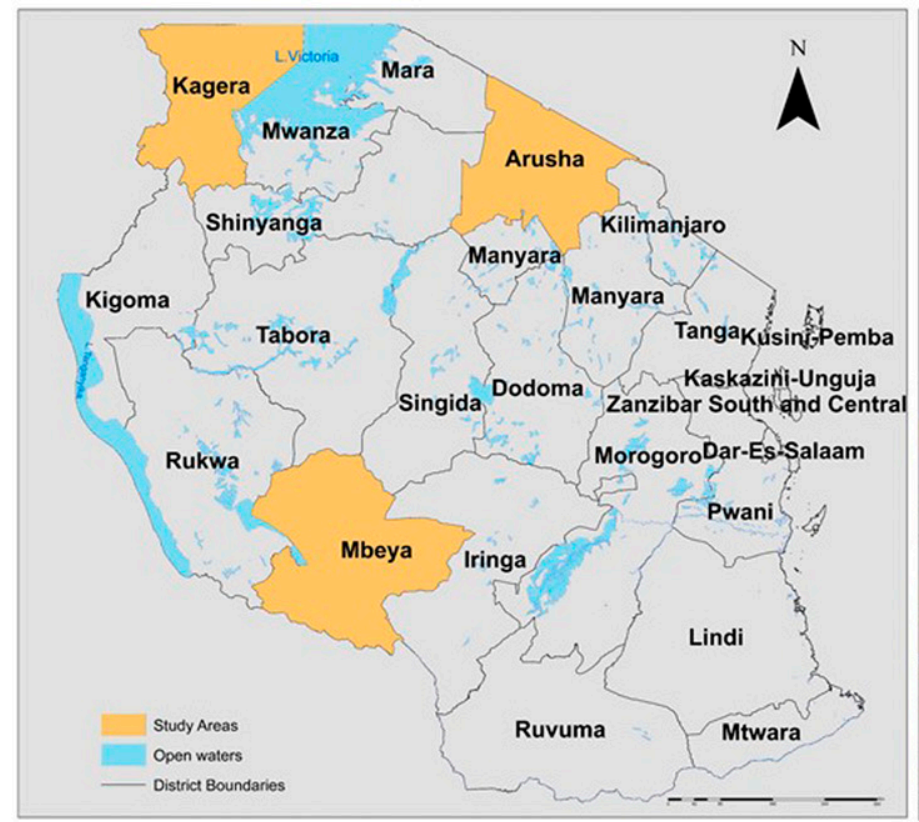

B

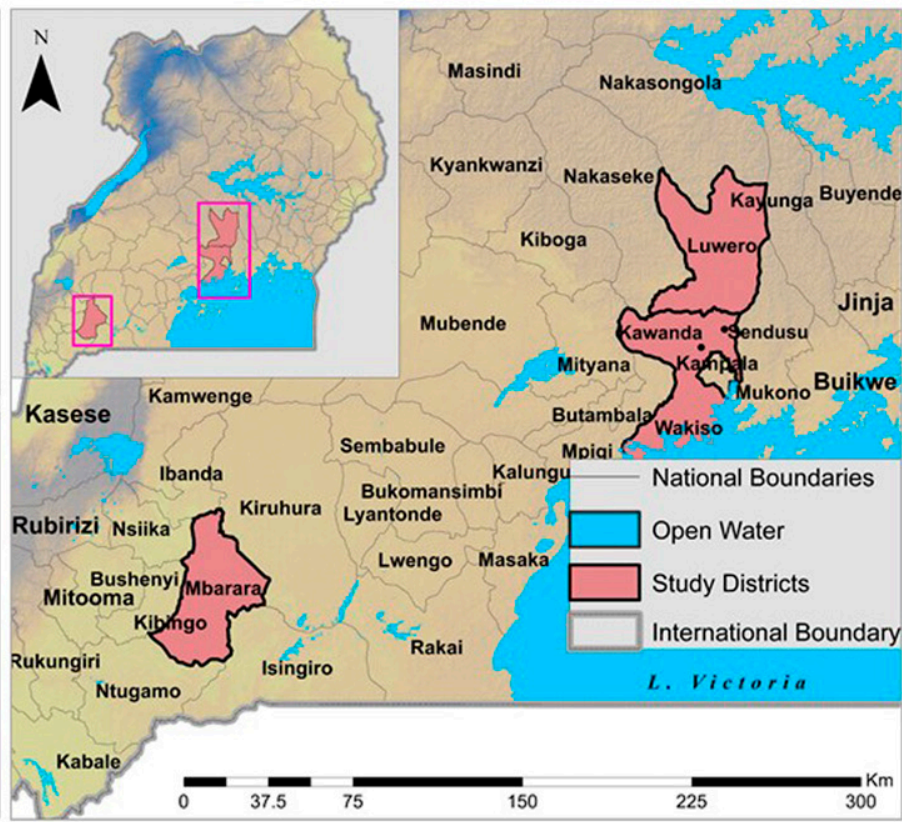

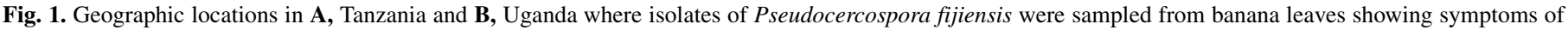
black Sigatoka. 
A previously described method (Stover 1976) for ascospore discharge was used to isolate $P$. fijiensis from the banana leaf samples. The leaves were first surface-sterilized with $1.5 \%$ sodium hypochlorite $(\mathrm{NaClO})$ for $90 \mathrm{~s}$, rinsed twice in sterile distilled water, blotted dry on a sterile paper towel, and viewed under a stereo microscope. Lesions with pseudothecia were cut into $2 \times 4-\mathrm{cm}$ discs, stapled onto a sterile filter paper with the adaxial side facing up, and dipped in sterile distilled water for 5 to $7 \mathrm{~min}$. The filter paper with the leaf disc was placed inside the lid of a Petri dish covering a $3 \%$ water agar plate. The plates were sealed and incubated at 25 to $27^{\circ} \mathrm{C}$ with $12 \mathrm{~h}$ of natural light. After $24 \mathrm{~h}$, the agar below the leaf was scanned for germinating ascospores using a stereo microscope (Motic K-700L; Motic, Hong Kong, China) at $10 \times$ magnification. Single ascospores were aseptically transferred onto V8 media ( $3 \mathrm{~g}$ of $\mathrm{CaCO}_{3}, 15 \mathrm{~g}$ of agar, $200 \mathrm{ml}$ of $\mathrm{V} 8$ juice), supplemented with cefotaxime at $200 \mathrm{mg} / \mathrm{liter}$, and incubated at 25 to $27^{\circ} \mathrm{C}$ under a white light with a 12 -h photoperiod for 28 to 35 days. Recovered fungal isolates were preserved on $15 \%$ glycerol and stored at $-80^{\circ} \mathrm{C}$ at the IITA laboratories in Uganda or Tanzania, depending on the country of origination. Another 22 samples of DNA of P. fijiensis were obtained from IITA in Ibadan, Nigeria, and included in the study. The Nigerian isolates had originally been collected from IITA's banana research stations located in Onne and Ibadan, Nigeria, in 2017 (Supplementary Table S1).

DNA extraction. Approximately $150 \mathrm{mg}$ of mycelia was scraped from 28- to 35-day-old cultures, and DNA was extracted using the protocol of Mahuku (2004), with the following modifications: fungal mycelia were macerated at room temperature using a mortar and pestle with sterile sea sand, DNA was precipitated by adding isopropanol, and the mixture was incubated overnight at $-20^{\circ} \mathrm{C}$. DNA quality and quantity were determined using a NanoDrop 2000C spectrophotometer (Thermo Fisher Scientific Inc., Pittsburgh, PA).

Identification of $\boldsymbol{P}$. fijiensis. Isolates of $P$. fijiensis and DNA from Nigeria were identified using species-specific primers and PCR (Arzanlou et al. 2007). Briefly, PCR was performed in $15 \mu \mathrm{l}$ of reaction mixture comprising $0.26 \mu \mathrm{M}$ of the primers MFActF $\left(5^{\prime}\right.$ CTCATGAAGATCTTGGCTGAG-3') and ACTR (5'-TCCAACCGT GAGAAGATGAC-3'), $1.5 \mathrm{mM} \mathrm{MgCl}_{2}, 0.2 \mu \mathrm{M}$ dNTPs, $1 \times$ PCR reaction buffer, and $0.6 \mathrm{U}$ of Top Taq polymerase (Bioneer Corporation, Deajeon, Korea). The cycling conditions were the same as those described by Arzanlou et al. (2007). The PCR products were resolved on a $1.5 \% \mathrm{wt} / \mathrm{vol}$ agarose gel in $1 \times$ TAE buffer at $150 \mathrm{~V}$ for $45 \mathrm{~min}$, stained with ethidium bromide, and viewed under ultraviolet light using a GBOX Syngene gel documentation system (Syngene, Cambridge, UK).

SSR genotyping. Eighteen SSR markers previously used to genotype a global collection of $P$. fijiensis (Robert et al. 2012) were used to genotype the 390 single spore isolates of $P$. fijiensis collected during the current study, including those isolates from Nigeria. Amplifications were conducted in three multiplex panels, each comprised of six markers. Each of the forward primers was labeled at the $5^{\prime}$ end with either FAM, VIC, NED, or PET dyes (Supplementary Table S2). Reactions were performed in a volume of $10 \mu \mathrm{l}$ comprising $5 \mu \mathrm{l}$ of multiplex PCR Master Mix (2×) (Qiagen, Valencia, CA, U.S.A.), $1 \mu \mathrm{l}(5 \times)$ of Q-solution, $1 \mu \mathrm{l}$ of DNA (20 ng/ $\mu \mathrm{l})$, and $0.5 \mu \mathrm{l}$ of a mix of the six primers at concentrations between 0.05 and $0.2 \mu \mathrm{m}$.

PCR amplifications included initial denaturation for $5 \mathrm{~min}$ at $95^{\circ} \mathrm{C}$, followed by 35 cycles of $30 \mathrm{~s}$ at $95^{\circ} \mathrm{C}$, annealing for $90 \mathrm{~s}$ at $57^{\circ} \mathrm{C}$, extension for $30 \mathrm{~s}$ at $72^{\circ} \mathrm{C}$, and a final step of $30 \mathrm{~min}$ at $68^{\circ} \mathrm{C}$. PCR amplicons were analyzed on an ABI Prism 3130XL genetic analyzer (Applied Biosystems) at the Central Analytical Facility (Stellenbosch University, Stellenbosch, South Africa). Alleles were called using GeneMarker V3.0.0 Software (Softgenetics, State College, PA). A multilocus data matrix was generated for all 390 isolates.

Mating type determination. Pseudocercospora fijiensis mating types were determined using previously developed mating type-specific primer pairs Mat1F/Mat1R and Mat2F/Mat2R to amplify mating type 1 (MAT1-1) and mating type 2 (MAT1-2) regions, respectively (Arzanlou et al. 2010). PCR was conducted in a $15-\mu$ reaction volume containing $0.4 \mu \mathrm{M}$ of each primer, $1.5 \mathrm{mM}$ $\mathrm{MgCl}_{2}, 0.7 \mu \mathrm{M}$ dNTPS, $1 \mathrm{U}$ of Top Taq polymerase, and $1 \%$, vol/ vol, bovine serum albumin. PCR cycling conditions were $95^{\circ} \mathrm{C}$ for $7 \mathrm{~min}$, followed by 35 cycles at $94^{\circ} \mathrm{C}$ for $25 \mathrm{~s}, 60^{\circ} \mathrm{C}$ for $45 \mathrm{~s}, 72^{\circ} \mathrm{C}$ for $1 \mathrm{~min}$, and a final extension at $72^{\circ} \mathrm{C}$ for $5 \mathrm{~min}$. Amplification products were resolved and visualized as previously described (Arzanlou et al. 2010). PCR products of 11 randomly selected isolates representing each region, including those yielding MAT1-1 fragments (702 bp), MAT1-2 fragments (720 bp), and samples yielding both fragments, were purified using a MSB Spin PCRapace kit (Biocompare, San Francisco, CA) following the manufacturer's protocol. Purified PCR products were used as a template in sequencing reactions conducted using the BigDye Terminator cycle sequencing Kit (Applied Biosystems) according to the manufacturer's recommendations. Sequencing reactions were performed in a 10- $\mu$ l volume comprising $4 \mu \mathrm{l}$ of BigDye Terminator mix (Applied Biosystems), 3.2 pmol of either MAT1-1 or MAT1-2 primers, and $200 \mathrm{ng} / \mu \mathrm{l}$ of the purified PCR product. The cycling conditions included an initial denaturation at $95^{\circ} \mathrm{C}$ for $5 \mathrm{~min}$, annealing at $55^{\circ} \mathrm{C}$ for $10 \mathrm{~s}$, and a final extension at $72^{\circ} \mathrm{C}$ for $4 \mathrm{~min}$. Samples were sequenced using a 3130 Genetic Analyzer (Applied Biosystems) at the Central Analytical Facility. Sequences were aligned using Geneious Prime software version 2019.0.3 (Biomatters, Auckland, New Zealand) and consensus sequences BLASTed against the NCBI sequence database.

Data analysis. Two of the SSR markers, MfSSR313 and MfSSR303, were monomorphic; they were removed from further analyses. All analyses were conducted in R (R Core Team 2018) using the package poppr (Kamvar et al. 2014), unless specified otherwise. A genotype accumulation curve was generated to assess whether the 16 loci used in this study were sufficiently informative to distinguish all MLGs.

A genetic and genotypic diversity data analysis was performed for all isolates of non-clone-corrected and/or clone-corrected data (containing only one unique MLG per subpopulation) to avoid overrepresentation of genotypes within a population. Locus-based statistics, including marker polymorphisms, gene diversity, and Shannon's information index, were calculated for each locus using the program GenAlEx version 6.502 (Peakall and Smouse 2012). The polymorphic information content for each locus was estimated using an online polymorphic information content calculator (Amiryousefi et al. 2018). Non-clone-corrected data were used to calculate gene diversity indices, including the average number of alleles/locus $(\mathrm{Na})$, private alleles, and effective number of alleles $(\mathrm{Ne})$, using GenAlEx. Unbiased expected heterozygosity, defined as $H_{\exp }=\left[\left(1-\sum \mathrm{pi}^{2}\right) \times(\mathrm{n} / \mathrm{n}-1)\right]$, where $\mathrm{p}$ is the allele frequency at a locus and $\mathrm{n}$ is the number of observed alleles at each locus (Grünwald et al. 2003; Nei 1978), was calculated using poppr.

For population-level and subpopulation-level statistics, genotypic diversity was calculated using Simpson's index $(D)$ (Simpson 1949 ) and Stoddart and Taylor's index $(G)$ (Stoddart and Taylor 1988). Samples that shared the same allelic pattern across the 16 loci were treated as clones (belonging to the same MLG). The number of expected multilocus genotypes (eMLGs) was determined to account for differences in sample sizes and to facilitate comparisons of MLGs at the smallest shared population size. The number of eMLGs was estimated based on rarefaction curves using 1000 bootstrapped samples (Grünwald et al. 2003). The function mlg.crosspop in poppr was used to detect the presence of repeated MLGs occurring across populations. The genotypic evenness, which determines the distribution of genotypes within a population, was calculated using the index E5 (Ludwig and Reynolds 1988). E5 ranges from 0 to 1, with 0 indicating that the population is dominated by a single MLG and 1 indicating that all genotypes occur at the same frequency. 
A linkage disequilibrium (LD) analysis was used to infer the reproductive strategy of $P$. fijiensis based on the index of association $\left(I_{A}\right)$ and the standardized index of association $\left(\bar{r}_{d}\right)$. The variables were calculated based on 999 permutations (Brown et al. 1980) and implemented using poppr. The standardized index of association (unlike $I_{A}$ ) is not correlated to the number of loci. The extent of LD was tested under the assumption that alleles observed at different loci are unlinked and in random association in these populations (Agapow and Burt 2001).

An exact binomial test (two-tailed) for goodness-of-fit was used to determine whether the observed mating-type frequencies within subpopulations deviated from the $1: 1$ ratio that would indicate equilibrium at each subpopulation. Isolates with double mating types were excluded from this analysis. Analyses of mating-type data were performed using SAS version 9.4 (SAS Institute, Cary, NC).

An analysis of molecular variance (AMOVA) was performed in Arlequin version 3.5.2 (Excoffier and Lischer 2010) using both clone-corrected and non-clone-corrected data to test whether $P$. fijiensis populations were genetically differentiated and to assess how genetic variations were distributed among populations (countries) and subpopulations (banana-growing regions in countries) based on 1000 permutations at $\alpha=0.5$.

The population structure of $P$. fijiensis was investigated using a discriminant analysis of principal components (DAPC) to determine any clusters of genetically related isolates (Jombart et al. 2010). The analysis aims to display differences between clusters of genetically distinct individuals while minimizing variations within clusters. The DAPC assumes no prior knowledge of group membership. Using the clone-corrected data set, the DAPC was performed using the function xvaldapc from the $\mathrm{R}$ package adegenet (Jombart 2008). For the DAPC analyses, the number of principal components (PCs) corresponding to the lowest mean squared error was selected via cross-validation with a training set consisting of $90 \%$ of the data (Jombart and Collins 2015). To estimate the optimal number of genetic clusters of MLGs in the data set, the K-means procedure was implemented in the function "find.cluster' to infer $\mathrm{K}$, which is the optimal number of clusters based on all of the combined samples (Supplementary Fig. S1). The number of clusters, $\mathrm{K}$, was determined using an interactive model based on changes in the value of the Bayesian Information Criterion (Jombart et al. 2010). The minimal value of $\mathrm{K}$ (just

TABLE 1. Characterization of 16 simple sequence repeat (SSR) markers used to screen the genetic diversity of 319 Pseudocercospora fijiensis isolates from Tanzania and Uganda ${ }^{\mathrm{a}}$

\begin{tabular}{lrcccc}
\hline SSR marker & Na & Ne & I & $u H e$ & PIC \\
\hline MfSSR324 & 3 & 1.47 & 0.41 & 0.29 & 0.59 \\
MfSSR428 & 3 & 1.66 & 0.52 & 0.36 & 0.59 \\
MfSSR412 & 2 & 1.60 & 0.49 & 0.35 & 0.37 \\
MfSSR319 & 5 & 1.53 & 0.49 & 0.29 & 0.77 \\
MfSSR305 & 2 & 1.32 & 0.37 & 0.24 & 0.37 \\
MfSSR061 & 5 & 1.82 & 0.70 & 0.44 & 0.77 \\
MfSSR430 & 2 & 1.37 & 0.33 & 0.23 & 0.37 \\
MfSSR403 & 4 & 1.72 & 0.58 & 0.38 & 0.70 \\
MfSSR424 & 6 & 1.21 & 0.31 & 0.16 & 0.81 \\
MfSSR406 & 3 & 1.31 & 0.32 & 0.20 & 0.59 \\
MfSSR362 & 2 & 1.15 & 0.16 & 0.10 & 0.37 \\
MfSSR340 & 3 & 1.09 & 0.15 & 0.08 & 0.59 \\
MfSSR401 & 2 & 1.07 & 0.11 & 0.06 & 0.37 \\
MfSSR355 & 2 & 1.09 & 0.15 & 0.08 & 0.37 \\
MfSSR407 & 3 & 1.50 & 0.44 & 0.30 & 0.59 \\
MfSSR425 & 2 & 1.31 & 0.31 & 0.20 & 0.37 \\
Total & 49 & 1.39 & 0.37 & 0.23 & 0.54 \\
\hline
\end{tabular}

a SSR markers adapted from (Robert et al. 2012; Zapater et al. 2008). Na, number of alleles per locus; Ne, effective number of alleles; I, Shannon's information index; $u H e$, unbiased haploid gene diversity, which is the measure of gene diversity (Nei 1978) per locus; PIC, polymorphic information content. before the Bayesian Information Criterion begins to increase or the minimum point at which it has leveled off) can be used to select $\mathrm{K}$ for the DAPC analyses. Finally, genetic relatedness among MLGs was assessed by calculating Bruvo's genetic distance using poppr (function bruvo.msn) and visualized using a minimumspanning network (MSN).

\section{RESULTS}

Sampling and species identification. Colonies of the singleascospore isolates were visible on V8 media 5 days after isolation. The color of the colonies was white, pinkish, or gray, with a dark green to black lower surface. Colonies were slightly raised with either regular or irregular edges, and the surfaces were smooth or had undulations (Supplementary Fig. S2). Isolate recovery per plant and per farm were low because of contamination during isolation; therefore, isolates collected from different leaves and farms in a region were pooled and chosen to represent single subpopulations. A total of 368 single-ascospore isolates were recovered (Supplementary Table S2) and identified as $P$. fijiensis using speciesspecific primers. DNA from the 22 samples of $P$. fijiensis from Nigeria were obtained from single-ascospore isolates stored at the IITA laboratories in Ibadan.

Allelic diversity analysis. Seventy-one isolates did not consistently produce an amplicon with most of the SSR markers; therefore, they were excluded from the study. The remaining 319 isolates of $P$. fijiensis were genotyped using the 16 SSR markers; in $100 \%$ of cases, they reliably produced an amplicon. A total of 49 alleles were identified. The number of alleles per locus varied from 2 for SSR markers MfSSR412, MfSSR305, MfSSR362, MfSSR401, and MfSSR355 to 6 for SSR marker MfSSR424, with an average number of alleles per locus of 3.1 (Table 1). The effective number of alleles per locus (Ne) ranged from 1.07 (MfSSR340) to 1.82 (MfSSR061), with an average of 1.39. The mean Shannon's information index was 0.37; it ranged from 0.11 (MfSSR401) to 0.71 (MfSSR 061). Nei's unbiased diversity $(u H e)$ per marker was low; it varied from 0.06 (MfSSR401) to 0.44 (MfSSR061), with an average of 0.23. The marker polymorphic information content was 0.37 for markers MfSSR 412, MfSR305, MfSSR362, MFSSR 401, MfSSR 430, MfSSR355, and MfSSR425; it was 0.81 for MfSSR424.

Genotypic diversity. There were a total of 296 MLGs among the 319 isolates of $P$. fijiensis sampled, and a total of 270 MLGs when assessed at the level of the subpopulations (Table 2). The genotype accumulation curve showed that $100 \%$ of the MLGs were sufficiently resolved with only 15 markers (Supplementary Fig. $\mathrm{S} 3$ ). The overall clonal fraction (CF) was $7 \%$. Among populations, the highest CF (26\%) was observed for the Arusha population; however, for Mbeya and Kagera, each isolate was a unique MLG (Fig. 2). Six MLGs were shared between populations and subpopulations. For example, a single MLG was shared between Luwero and Nigeria and between Mbeya and Sendusu. A total of four MLGs were shared between subpopulations in Uganda. Most MLGs were represented by a single isolate (singletons) in all populations. Only two MLGs were represented by more than two isolates (Fig. 2).

The even distribution of genotypes is indicated by $E 5>0.5$. With the non-clone-corrected data, the lowest E5 was found in Arusha (0.7) and the highest was found in Mbeya (1.00). Although similar, the $E 5$ for the population from Uganda (0.86) was slightly higher compared with that for the population from Tanzania (0.77) (Table 2). The eMLG was also highest for Mbeya (21), for which every individual was a unique MLG, and it was lowest for Arusha (16.2). The Shannon-Weiner index $(\mathrm{H})$ and Stoddard-Taylor genotypic diversity indices were highest for the subpopulation from Luwero $(\mathrm{H}=4.31 ; \mathrm{G}=72.7)$ and lowest for the subpopulation from Arusha $(\mathrm{H}=2.91 ; \mathrm{G}=13.2)$ (Table 2). Arusha also had the lowest genetic diversity $\left(\mathrm{H}_{\exp }=0.12\right)$. Luwero and Sendusu had moderate genetic diversity $\left(\mathrm{H}_{\mathrm{exp}}=0.31\right)$. The genetic diversity of 
the P. fijiensis population from Uganda $\left(\mathrm{H}_{\mathrm{exp}}=0.29\right)$ was similar but slightly more genetically diverse compared with the population from Tanzania $\left(\mathrm{H}_{\exp }=0.25\right)$. Private alleles were found in all subpopulations in Uganda and in one subpopulation in Tanzania (Table 2).

Mating-type frequencies and linkage disequilibrium. The $368 \mathrm{P}$. fijiensis isolates were screened for mating-type frequencies. As expected, a 702-bp amplicon was obtained using the MAT1-1 primers, and a 720-bp amplicon was obtained using MAT1-2 primers. MAT1-1 and MAT1-2 were found in all subpopulations except Mbeya, where only MAT1-1 was present. Of the 368 isolates, 200 were MAT1-1 and 146 isolates were MAT12. The remaining 22 isolates were identified as having both MAT1-1 and MAT1-2 types present (Table 3). The MAT1-1 and MAT1-2 amplicons of selected isolates were sequenced and compared with the nucleotide database of the NCBI Genebank using BLAST to determine the closest match based on the maximal percentage identity. Sequences of selected MAT1-1 isolates showed $>99 \%$ similarity to $M$. fijiensis isolate DQ787015.1, whereas the MAT1-2 gene had $>99 \%$ similarity to $M$. fijiensis isolate DQ787016.1. Isolates amplifying both mating types had similar matches with isolates DQ787015.1 and DQ787016.1. Sequences of both mating types were deposited at NCBI GenBank (accession numbers MT681642 to MT681652).

Opposite mating types were isolated from the same leaf (in close proximity, $4 \mathrm{~cm}^{2}$ ), from the same farm (data not shown), and from the same subpopulation (Table 3). However, in Tanzania at Mbeya, all isolates recovered were $M A T 1-1$; at Kagera, all isolates were MAT1-2 (Table 3). The exact binomial test to determine equilibrium of mating types (excluding isolates with double mating types) indicated that MAT1-1 was over-represented in Uganda at Sendusu based on both the non-clone-corrected $(P=0.003)$ and clonecorrected $(P=0.002)$ data, in Tanzania at Arusha based on the nonclone-corrected data $(P=0.004)$ only, and at Mbeya based on both the non-clone-corrected $(P<0.0001)$ and clone-corrected data $(P=$ 0.01). All other subpopulations (Kawanda, Luwero, and Mbarara) were at equilibrium for the mating type. The mating types were in equilibrium for the Uganda population $(P=0.52$ for non-clonecorrected and $P=0.18$ for clone-corrected data); however, for the Tanzania population, mating types were not in equilibrium $(P=$ 0.001 for non-clone-corrected and $P=0.003$ for clone-corrected data). When analyzed using isolates from all subpopulations from both populations (Tanzania and Uganda combined), the mating types were not in equilibrium regardless of whether the data were clone-corrected $(P=0.01)$ or non-clone-corrected $(P=$ 0.003). MAT1-1 predominated. However, there was no evidence for LD in any of the subpopulations based on the clone-corrected and non-clone-corrected data sets (Table 4; Supplementary Fig. S4). Similarly, all values of $\bar{r}_{d}$ were nonsignificant $(P>0.05)$ (Table 4; Supplementary Fig. S4), indicating random mating.

Population genetic differentiation. The AMOVA revealed significant population differentiation $(P=0.001)$ (Table 5). Most variations were found at the scale of isolates within subpopulations, accounting for 90 and $91 \%$ of the genetic variations in non-clonecorrected and clone-corrected data, respectively. Variations among subpopulations accounted for only $6 \%$ of the total genetic variation, indicating very low levels of differentiation at the scale of the subpopulation, whereas variations between populations (countries) accounted for just 4 and $3 \%$ of the variations in non-clone-corrected and clone-corrected data, respectively.

Population structure. The DAPC showed no clear clustering among isolates of $P$. fijiensis collected from different subpopulations, including those collected from Nigeria (Fig. 3). However, a degree of clustering of the isolates from Arusha was evident. Membership probability for each isolate, as determined by DAPC, was used to visualize the distribution of cluster assignments within and between populations (Fig. 4). Membership probability assignments did not reveal high levels of population differentiation because each genotype had similar probabilities of membership with each cluster. However, most isolates from Arusha had a higher probability of assignment to a cluster separate from any other region. Similarly, the MSN based on Bruvo's genetic distance did

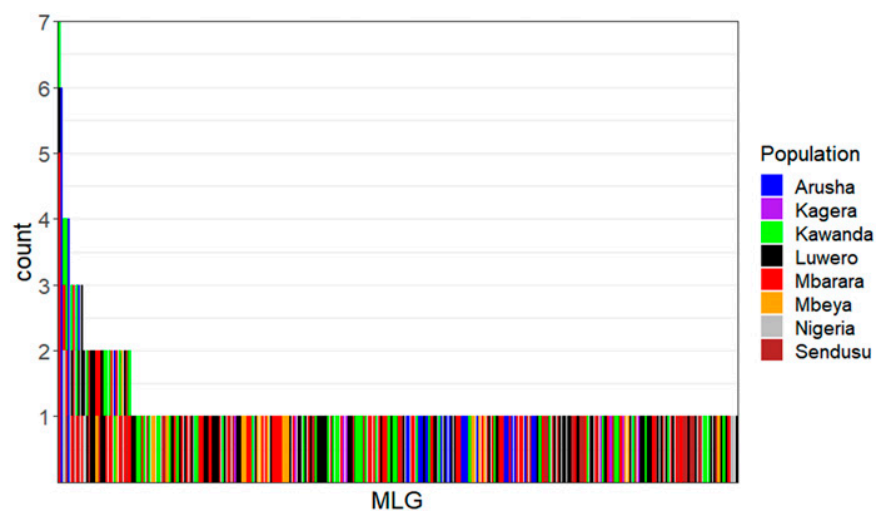

Fig. 2. Bar plot showing the abundance of multilocus genotypes (MLGs) shared between banana-growing regions in Uganda, Tanzania, and Nigeria. Each bar represents a unique MLG and the number of isolates in a population, with the colored portions of each bar corresponding to the number of isolates with that MLG in each population.

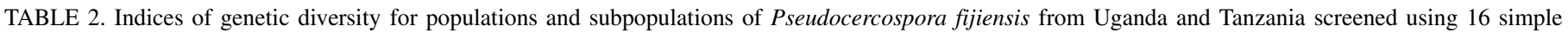
sequence repeat markers ${ }^{\mathrm{a}}$

\begin{tabular}{|c|c|c|c|c|c|c|c|c|c|c|c|}
\hline Population (country) & Subpopulation (region) & $\mathrm{N}$ & MLG & $\mathrm{CF}(\%)$ & eMLG & $\mathrm{H}$ & $\mathrm{G}$ & Lambda & E5 & $\mathrm{H}_{\exp }$ & $\mathrm{Pa}$ \\
\hline \multirow[t]{3}{*}{ Tanzania } & Arusha & 31 & 23 & 26 & 16.2 & 2.91 & 13.2 & 0.92 & 0.70 & 0.12 & - \\
\hline & Kagera & 8 & 8 & 0 & - & - & - & - & - & - & 1 \\
\hline & Mbeya & 21 & 21 & 0 & 21.0 & 3.04 & 21.0 & 0.95 & 1.00 & 0.26 & - \\
\hline Subtotal & & 60 & 52 & 13 & 9.5 & 3.82 & 35.3 & 0.97 & 0.77 & 0.25 & 1 \\
\hline \multirow[t]{4}{*}{ Uganda } & Kawanda & 58 & 56 & 4 & 20.7 & 4.01 & 54.3 & 0.98 & 0.98 & 0.24 & 1 \\
\hline & Luwero & 80 & 76 & 5 & 20.7 & 4.31 & 72.7 & 0.99 & 0.97 & 0.31 & 1 \\
\hline & Mbarara & 70 & 65 & 7 & 20.3 & 4.11 & 53.3 & 0.98 & 0.87 & 0.27 & 5 \\
\hline & Sendusu & 46 & 43 & 7 & 20.4 & 3.74 & 40.7 & 0.98 & 0.97 & 0.31 & 6 \\
\hline Subtotal & & 254 & 221 & 13 & 9.9 & 5.32 & 177.2 & 0.99 & 0.86 & 0.29 & 13 \\
\hline Nigeria & Ibadan & 5 & 4 & 2 & - & - & - & - & - & - & 2 \\
\hline Total & & 319 & 296 & 7 & 20.6 & 5.50 & 205 & 0.99 & 0.84 & 0.29 & 16 \\
\hline
\end{tabular}

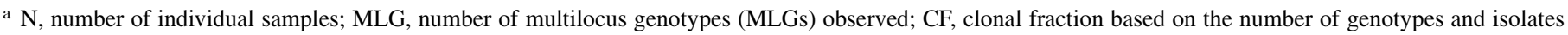
per subpopulation: $\mathrm{CF}=1$ - (number of MLGs/total number of isolates); eMLG, number of expected MLG at the smallest sample size 21 based on rarefaction (Hurlbert 1971); H, Shannon-Wiener Index of MLG diversity (Shannon 2001); G, Stoddart and Taylor's Index of MLG diversity (Stoddart and Taylor 1988); Lambda, Simpson's index; E5, evenness (Grünwald et al. 2003; Ludwig and Reynolds 1988); Hexp, Nei's 1978 expected heterozygosity (Nei 1978); Pa, number of private alleles. Dashes indicate that diversity indices of these populations were not calculated because of the small population size. 
not cluster isolates according to geographic origin and was consistent with the DAPC analysis (Fig. 5).

\section{DISCUSSION}

High genotypic diversity was observed within all subpopulations of $P$. fijiensis sampled from banana in Tanzania and Uganda, with little evidence for regional differentiation, which is indicative of a common origin or frequent exchange of genetic material (McDonald 1997). Tests for LD showed that the loci in all populations were in equilibrium, which supports the contention of frequent recombination through sexual reproduction (Milgroom 1996) in P. fijiensis in East Africa. Mating types were in equilibrium in some subpopulations, but not in others, which could indicate a component of asexual reproduction in some cases. A moderate level of genetic diversity $\left(\mathrm{H}_{\exp }=0.12\right.$ to 0.31$)$ was observed in the subpopulations in East Africa, unlike populations from Papua New Guinea and the Philippines in Southeast Asia that exhibited high genetic diversity $\left(\mathrm{H}_{\mathrm{exp}}=0.62\right)$ (Carlier et al. 1996; Rivas et al. 2004; Robert et al. 2010). Our finding is similar to that of Robert et al. (2010), who indicated less variability in the African populations of $P$. fijiensis using the same set of SSR markers. The lower diversity probably reflects the relatively recent arrival of the pathogen in East Africa compared with Southeast Asia, which is the center of origin for P. fijiensis (Carlier et al. 1996; Robert et al. 2012; Saville et al. 2017). Robert et al. (2012) concluded that the lower genetic diversity of the African populations of $P$. fijiensis is attributable to a single introduction event of a few ancestral isolates from a

TABLE 3. Mating-type frequencies of Pseudocercospora fijiensis in non-clone-corrected and clone-corrected data from Uganda and Tanzania

\begin{tabular}{|c|c|c|c|c|c|c|c|c|}
\hline \multirow[b]{2}{*}{ Population (country) } & \multirow[b]{2}{*}{ Subpopulation (region) } & \multirow[b]{2}{*}{$N$} & \multicolumn{3}{|c|}{ Non-clone-corrected } & \multirow[b]{2}{*}{$N$} & \multicolumn{2}{|c|}{ Clone-corrected } \\
\hline & & & MAT1-1: MAT1-2 $(\%)^{\mathrm{a}}$ & MAT1-1/MAT1-2 $(\%)^{\mathrm{b}}$ & $P$ value ${ }^{\mathrm{c}}$ & & MAT 1-1: MAT1-2 ${ }^{\mathrm{a}}$ & $P$ value ${ }^{\mathrm{c}}$ \\
\hline \multirow[t]{5}{*}{ Uganda } & Kawanda & 69 & $51: 43$ & 6 & 0.53 & 62 & $55: 45$ & 0.23 \\
\hline & Sendusu & 58 & $69: 31$ & 0 & 0.003 & 53 & $68: 32$ & 0.002 \\
\hline & Luwero & 89 & $38: 51$ & 11 & 0.21 & 68 & $47: 53$ & 0.47 \\
\hline & Mbarara & 77 & $45: 51$ & 4 & 0.64 & 64 & $48: 52$ & 0.76 \\
\hline & Subtotal & 293 & $49: 45$ & 6 & 0.52 & 247 & $54: 46$ & 0.18 \\
\hline \multirow[t]{4}{*}{ Tanzania } & Arusha & 35 & $68: 23$ & 9 & 0.004 & 28 & $71: 29$ & 0.06 \\
\hline & Kagera & 8 & $0: 75$ & 25 & - & 6 & $0: 100$ & - \\
\hline & Mbeya & 32 & 100:0 & 0 & $<0.001$ & 31 & 100:0 & 0.001 \\
\hline & Subtotal & 75 & $75: 19$ & 6 & 0.001 & 65 & $78: 22$ & 0.003 \\
\hline Total & & 368 & $54: 40$ & 6 & -0.003 & 312 & $59: 41$ & 0.01 \\
\hline
\end{tabular}

a The proportion (\%) of isolates belonging to each of the mating types in a population and subpopulation.

b Proportion of isolates with both mating types.

${ }^{c}$ Probability from an exact binomial analysis (two-tailed) used to test whether mating-type frequencies deviate significantly from a 1:1 ratio. Dashes indicate that analysis was not performed because of the low number of isolates.

TABLE 4. Measure of random mating based on linkage disequilibrium among 16 simple sequence repeat loci in subpopulations of Pseudocercospora fijiensis from Uganda and Tanzania

\begin{tabular}{|c|c|c|c|c|c|c|c|c|c|c|c|}
\hline \multirow[b]{2}{*}{ Population (country) } & \multirow[b]{2}{*}{ Subpopulation (region) } & \multirow[b]{2}{*}{$N$} & \multicolumn{4}{|c|}{ Non-clone-corrected } & \multirow[b]{2}{*}{$N$} & \multicolumn{4}{|c|}{ Clone-corrected } \\
\hline & & & $I_{A}{ }^{\mathrm{a}}$ & $P$ value & $\overline{\mathrm{r}}_{\mathrm{d}}^{\mathrm{b}}$ & $P$ value & & $I_{A}{ }^{\mathrm{a}}$ & $P$ value & $\overline{\mathrm{r}}_{\mathrm{d}}^{\mathrm{b}}$ & $P$ value \\
\hline \multirow{3}{*}{ Uganda } & Kawanda & 58 & -0.08 & 0.84 & -0.006 & 0.84 & 56 & -0.08 & 0.85 & -0.006 & 0.85 \\
\hline & Luwero & 80 & -0.06 & 0.80 & -0.004 & 0.80 & 76 & -0.07 & 0.86 & -0.005 & 0.86 \\
\hline & Mbarara & 70 & 0.06 & 0.80 & -0.003 & 0.82 & 65 & -0.12 & 0.96 & -0.01 & 0.96 \\
\hline \multirow[t]{2}{*}{ Tanzania } & Arusha & 31 & 0.12 & 0.23 & 0.01 & 0.23 & 23 & -0.1 & 0.73 & -0.01 & 0.73 \\
\hline & Kagera & 8 & $-^{c}$ & - & - & - & 8 & - & - & - & - \\
\hline Total & & 319 & 0.02 & 0.1 & 0.001 & 0.31 & 296 & 0.04 & 0.15 & 0.01 & 0.2 \\
\hline
\end{tabular}

a $I_{A}$, index of association (Agapow and Burt 2001; Brown et al. 1980).

$\mathrm{b} \overline{\mathrm{r}}_{\mathrm{d}}$, standardized $I_{A}$ (Agapow and Burt 2001).

${ }^{c}$ An analysis was not performed because of the low number of isolates.

TABLE 5. Hierarchical analysis of molecular variance (AMOVA) of populations of Pseudocercospora fijiensis from banana in Uganda and Tanzania ${ }^{\mathrm{a}}$

\begin{tabular}{|c|c|c|c|c|c|c|c|}
\hline Data & Source & df & SS & MS & Estimated variance & Variation (\%) & $P$ value $^{\mathrm{b}}$ \\
\hline \multirow[t]{4}{*}{ Non-clone-corrected } & Among populations & 2 & 37.34 & 18.67 & 0.24 & 4 & 0.08 \\
\hline & Among subpopulations & 5 & 51.52 & 10.3 & 0.18 & 6 & 0.07 \\
\hline & $\begin{array}{l}\text { Among isolates within } \\
\text { subpopulations }\end{array}$ & 311 & 774.36 & 2.49 & 2.49 & 90 & 0.001 \\
\hline & Total & 318 & 863.22 & & 0.42 & 100 & \\
\hline \multirow[t]{3}{*}{ Clone-corrected } & Among populations & 2 & 28.06 & 14.03 & 0.19 & 3 & 0.06 \\
\hline & Among subpopulations & 5 & 47.23 & 9.45 & 0.16 & 6 & 0.06 \\
\hline & $\begin{array}{l}\text { Among isolates within } \\
\text { subpopulations }\end{array}$ & 288 & 746.41 & 2.59 & 2.59 & 91 & 0.001 \\
\hline
\end{tabular}

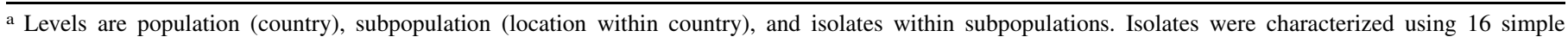
sequence repeats markers. df, degrees of freedom; SS, sum of squared observations; MS, mean squares.

b $P$ value based on 999 permutations. 
Southeast Asian population in the area of the South China Sea, followed by the spread of the pathogen across the African continent (Rivas et al. 2004; Robert et al. 2012).

High genotypic diversity, characterized by unique MLGs occurring as singletons, with no dominant MLGs was observed in the populations of $P$. fijiensis from both Uganda and Tanzania. An abundance of novel genotypes within populations indicated overall high genetic diversity and further demonstrated that variation in P. fijiensis occurs at microgeographic scales (Hayden et al. 2003). In this study, six genotypes were shared between countries and between regions within a country, highlighting the occurrence of gene flow among populations and subpopulations, or that there may be a common source of pathogen inoculum (McDonald and Linde 2002). Similar findings were reported in Nigeria, where geographically distinct regions shared clones (Zandjanakou-Tachin et al. 2009). However, because the pedigrees are not known, the results of this study could not discern whether the shared genotypes were identical by descent (IBD) or if they were identical by state (IBS).

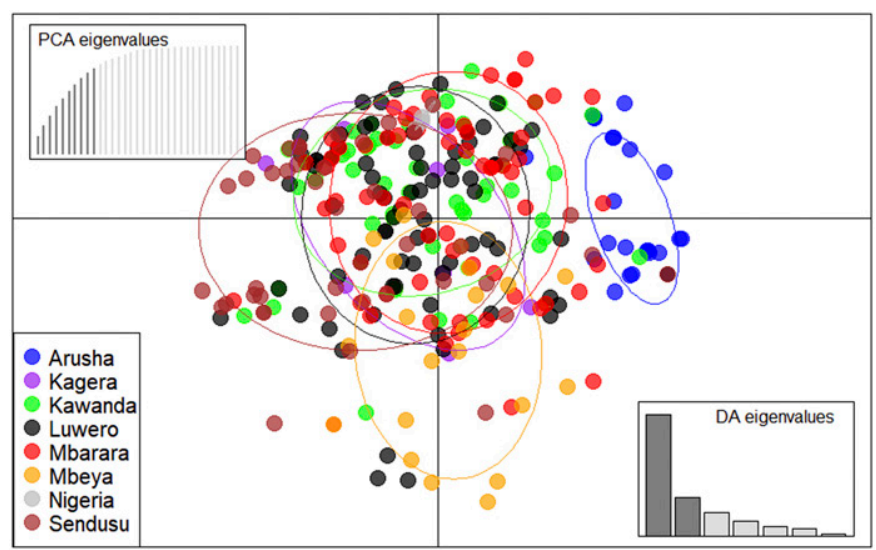

Fig. 3. A discriminant analysis of the principal components scatterplot of clone-corrected data showing clustering of Pseudocercospora fijiensis isolates from Uganda (Kawanda, Luwero, Mbarara, and Sendusu), Tanzania (Arusha, Kagera, and Mbeya) and Nigeria. Clusters representing each region are indicated by the color-coded ellipses. Dots represent multilocus genotypes (in each population). In the top left and bottom right corners, insets of the principal component analysis and discriminant analysis eigenvalues are shown, respectively.

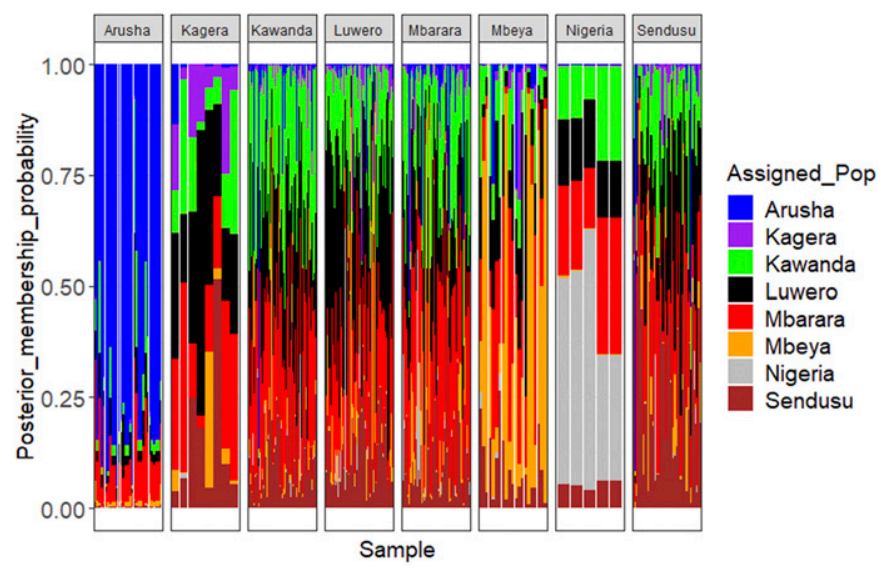

Fig. 4. A bar plot of clone-corrected data showing the population membership probability assignments of Pseudocercospora fijiensis against their original populations. Bars of the same color represent the likelihood of the same genetic cluster based on analysis of the single sequence repeat marker data. Bars of mixed colors are admixed individuals/isolates.
Populations from Nigeria and Luwero in Uganda shared one MLG. This was unexpected considering the geographic distance between the populations. However, Robert et al. (2012) also found MLGs that were shared between Uganda in East Africa and Ivory Coast in West Africa. Fahleson et al. (2009) reported that isolates from Uganda were genetically related to isolates from Ghana and Nigeria in West Africa. This implies that long-distance dispersal mechanisms have a major role in the dispersal of $P$. fijiensis. This could be through human-mediated transfer of infected planting materials or infected banana leaves commonly used for wrapping fruit during transportation (Ploetz 2001).

The subpopulation of $P$. fijiensis from Arusha was unique and did not contain MLGs that were shared with other regions. It had a high clonal fraction with low gene and genotypic diversity. These characteristics are consistent with those of a pathogen that reproduces predominantly asexually. However, there was no evidence of LD based on both the $I_{A}$ and $\bar{r}_{d}$ values, supporting the hypothesis of random mating. Therefore, the Arusha subpopulation can be differentiated from the other subpopulations by the likely occurrence of a few highly successful individuals that reproduce clonally (Milgroom 1996). The partial differentiation of the Arusha subpopulation could be explained by the proximity of the Arusha region to Pemba Island (300 to $400 \mathrm{~km}$ ), where the pathogen was first reported in East Africa (Dabek and Waller 1990), and a presumed point of entry of $P$. fijiensis into Africa (Pasberg-Gauhl et al. 2000). From Pemba, the pathogen may have been dispersed northward through Tanga to Kilimanjaro and Arusha via infected planting materials. The pathogen, however, failed to establish in the Kilimanjaro region, probably because of the cooler temperatures experienced at higher altitudes and volcanic soils rich in silicon (R. Swennen, personal communication). Low Sigatoka severity has been observed on bananas growing in soils with high silicon content (Kablan et al. 2012). Uptake of silicon by banana plants enhances resistance to $P$. fijiensis through activation of defense genes and formation of a mechanical or physical barrier that restricts pathogen penetration (Kablan et al. 2012), thus reducing pathogen proliferation, reproduction, and prevalence.

The Tengeru Horticulture Research farm in Arusha is bordered by national parks and areas where banana is not cultivated. The peripheral nature of the population may have restricted movement of the pathogen and precluded the diversity observed in other more accessible populations. The degree of differentiation between populations depends on migration and reproductive isolation (Milgroom 2015; Saville et al. 2017). Finally, because of restricted

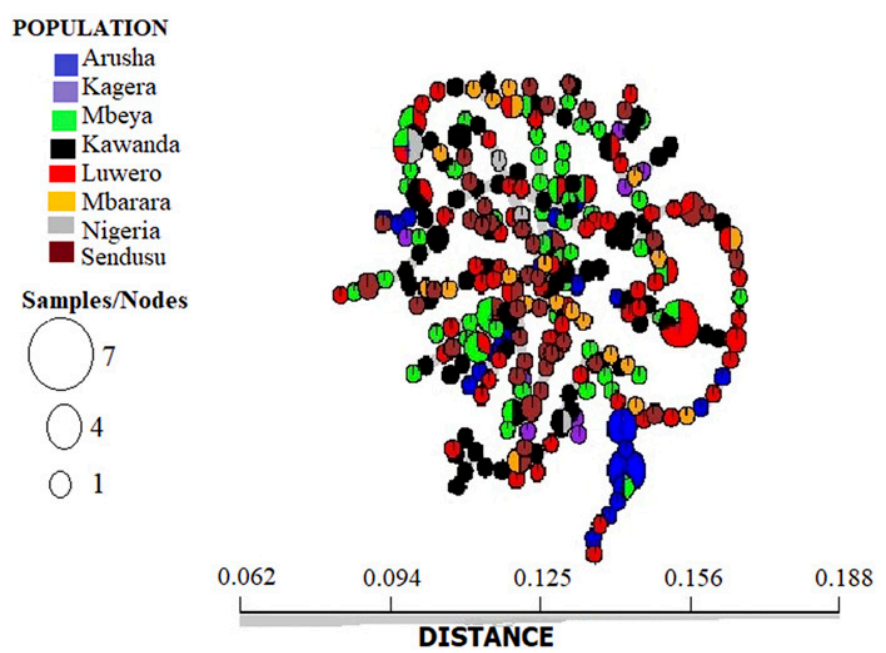

Fig. 5. A minimum spanning network based on clone-corrected data showing the relationships among individual multilocus genotypes (MLGs) of Pseudocercospora fijiensis from different populations in Tanzania and Uganda. Each node represents a different MLG. Distances between nodes are based on Bruvo's distance (Bruvo et al. 2004). Node sizes correspond to the number of individuals representing an MLG. 
migration and the resulting gene flow, selection may have acted to favor phenotypes well-adapted to the Arusha environment.

The measures of LD, $I_{\mathrm{A}}$, and $\bar{r}_{d}$ provided evidence of the random association of alleles, which is an indirect indication of sexual reproduction (Drenth et al. 1994). Recombination generates novel genotypes that differ from those of either parent, resulting in high genotypic diversity. Previous studies have shown that sexual reproduction has important epidemiological and evolutionary roles in the life cycle of $P$. fijiensis (Carlier et al. 1996; Hayden et al. 2003; Rivas et al. 2004; Saville et al. 2017). Recombination is probably the greatest driver of evolution in sexually reproducing organisms because it creates novel genetic variants with improved fitness (Milgroom 1996, 2015). The novel genotypes may have increased aggressiveness and/or virulence, with the potential to overcome host resistance or develop resistance to fungicides (McDonald and Mundt 2016). Furthermore, the overall clonal fraction in the subpopulations was very low (7\%), but it supported the contribution of asexual reproduction in defining the population structure of P. fijiensis. The low clonal fractions and high genotypic diversity are consistent with pathogens with a mixed mode of reproduction (Milgroom 2015), which are well-documented in $P$. fijiensis populations (Carlier et al. 2000).

$P$. fijiensis sexual reproduction has been described previously (Carlier et al. 2000; Churchill 2011). However, sexual reproduction depends on the availability of opposite mating types in proximity and the occurrence of suitable environmental conditions. With the exception of the Mbeya and Kagera subpopulations, both MAT1-1 and MAT1-2 were detected in all populations of $P$. fijiensis in Uganda and Tanzania. Opposite mating types were occasionally recovered from the same leaf, plant, and farm. The co-occurrence at small spatial scales increases the chances of sexual recombination. Mating types were in equilibrium in most subpopulations, which is expected for populations undergoing frequent sexual recombination, and consistent with the findings of Conde-Ferraez et al. (2010) and Queiroz et al. (2013), who reported mating-type equilibrium in populations of $P$. fijiensis in the Tabasco and Yucatan states in Mexico. However, recent observations in Mexico (Chiapas, Michoacan, Colimia, Oaxaca, Tabasco) found a mating-type distribution of 2:1 (Manzo-Sánchez et al. 2019), revealing the predominance of MAT1-1. Regular sexual reproduction underscores the importance of ascospores in the spread of the disease because they are primary sources of infections (Carlier et al. 2000; Churchill 2011). Mating types were not in equilibrium in the Sendusu, Mbeya, and Kagera subpopulations. Notably, MAT1-1 was absent from Kagera, and MAT1-2 was absent from Mbeya. Why these three subpopulations did not have mating types in equilibrium is unknown, but this might reflect better adaptation of one mating type compared with the other. Differential virulence between mating types has been observed in Mycosphaerella graminicola (Fuckel) Schroeter (Zhan et al. 2007). The resulting greater proliferation of the more virulent mating type increases its chances of being sampled (Conde-Ferráez et al. 2010; Zhan et al. 2002). More studies are required to determine the level of virulence of mating types of $P$. fijiensis.

The presence of both mating types in the same isolate of $P$. fijiensis was unexpected. The functionality of the two idiomorphs occurring in an isolate, however, was not ascertained in this study. The co-existence of both idiomorphs within a single isolate in this study was confirmed by DNA sequencing of the mating-type amplicons and based on the SSR genotyping, which showed that, in all cases, all 16 SSR primers amplified only a single allele at each locus (if these mixed mating-type isolates had been caused by mixed cultures, then the SSR primers would be expected to result in multiple amplicons at the same locus, at least in some cases). Furthermore, Arzanlou et al. (2010) reported the presence of a fused locus containing fragments of both the MAT-1 and MAT1-2 idiomorphs in some isolates of $P$. fijiensis. A similar organization of the fusion loci was also present in the closely related species $P$. musae and P. eumusae, which is indicative of a shared ancestor in which a fusion event between MAT1-1 and MAT1-2 may have occurred (Arzanlou et al. 2010). A pseudo-homothallic mating system has been documented in other ascomycetes, such as Neurospora tetrasperma and Podospora anserina and the basidiomycete Agaricus bisporus, which can maintain a stable heterokaryon (Grognet and Silar 2015). Pseudo-homothallic fungi have the benefits of heterothallism as well as the ability to self-cross in the absence of a mating partner (Bushley et al. 2013; Grognet and Silar 2015). The ability to form a stable heterokaryon in P. fijiensis isolates bearing a fused locus should be investigated.

The diverse colony morphologies we observed among isolates is consistent with cultural variations described for $P$. fijiensis (Leiva-Mora et al. 2008; Stover 1976). The relationship between these phenotypes and mating types, isolate origins, and genotypes was not established during this study, although this would be interesting to investigate.

Based on the risk framework model proposed by McDonald and Linde (2002), pathogens with high evolutionary potential pose a management challenge. The pathogens evolve rapidly and can readily overcome novel host resistance and develop resistance to the single-site mode of action fungicides. For successful resistance breeding, the presence of numerous MLGs within populations of $P$. fijiensis represents a challenge and necessitates the use of sufficient representation of the pathogenic diversity (both virulence and aggressiveness) to effectively screen for durable resistance in banana. Studies investigating the presence of pathogenic groups among isolates from different subpopulations are recommended to elucidate the epidemiological significance of the genetic variations observed in this study. Future research should seek to characterize effector protein repertoires in different $P$. fijiensis populations and their interactions with host resistance genes to guide the development of durable resistance. Continued monitoring of pathogen populations for the emergence of novel pathotypes is recommended, especially if future research in East Africa demonstrates the presence of $P$. fijiensis isolates differing in pathogenicity or virulence, as has been reported in other areas (Fullerton and Olsen 1995; Zandjanakou-Tachin et al. 2012).

\section{ACKNOWLEDGMENTS}

We thank Amos Alakonya for providing P. fijiensis DNA from Nigeria; Moses Nyine and Francis Onyilo for technical advice; and F. Musa, M. Njala, E. Were, A. Tazuba, and K. Jomanga for assistance during this study.

\section{LITERATURE CITED}

Agapow, P. M., and Burt, A. 2001. Indices of multilocus linkage disequilibrium. Mol. Ecol. Notes 1:101-102.

Alakonya, A. E., Kimunye, J., Mahuku, G., Amah, D., Uwimana, B., Brown, A., and Swennen, R. 2018. Progress in understanding Pseudocercospora banana pathogens and the development of resistant Musa germplasm. Plant Pathol. 67:759-770.

Amiryousefi, A., Hyvönen, J., and Poczai, P. 2018. iMEC: Online marker efficiency calculator. Appl. Plant Sci. 6:e01159.

Arzanlou, M., Abeln, E. C., Kema, G. H., Waalwijk, C., Carlier, J., de Vries, I., Guzmán, M., and Crous, P. W. 2007. Molecular diagnostics for the Sigatoka disease complex of banana. Phytopathology 97:1112-1118.

Arzanlou, M., Crous, P. W., and Zwiers, L. H. 2010. Evolutionary dynamics of mating-type loci of Mycosphaerella spp. occurring on banana. Eukaryot. Cell 9:164-172.

Brown, A. H. D., Feldman, M. W., and Nevo, E. 1980. Multilocus structure of natural populations of Hordeum spontaneum. Genetics 6:523-536.

Bruvo, R., Michiels, N. K., D'Souza, T. G., and Schulenburg, H. 2004. A simple method for the calculation of microsatellite genotype distances irrespective of ploidy level. Mol. Ecol. 13:2101-2106.

Bushley, K. E., Li, Y., Wang, W. J., Wang, X. L., Jiao, L., Spatafora, J. W., and Yao, Y. J. 2013. Isolation of the MAT1-1 mating type idiomorph and evidence for selfing in the Chinese medicinal fungus Ophiocordyceps sinensis. Fungal Biol. 117:599-610.

Carlier, J., Foure, E., Gauhl, F., Jones, D. R., Lepoivre, P., Mourichon, X., Pasberg-Gaughl, C., and Romero, R. A. 2000. Fungal diseases of the foliage; Sigatoka leaf spots. Pages 37-141 in Diseases of Banana, Abaca, and Enset. D. R. Jones, ed. CAB International, Wallingford, U.K. 
Carlier, J., Lebrun, M. H., Zapater, M. F., Dubois, C., and Mourichon, X. 1996. Genetic structure of the global population of banana black leaf streak fungus, Mycosphaerella fijiensis. Mol. Ecol. 5:499-510.

Churchill, A. C. 2011. Mycosphaerella fijiensis, the black leaf streak pathogen of banana: progress towards understanding pathogen biology and detection, disease development, and the challenges of control. Mol. Plant Pathol. 12: 307-328.

Conde-Ferráez, L., Grijalva-Arango, R., Canto-Canché, B. B., Manzo-Sánchez, G., Canul-Salazar, M. I., and James, A. C. 2010. The development of mating type-specific primers for Mycosphaerella fijiensis, the causal agent of black Sigatoka of banana, and analysis of the frequency of idiomorph types in Mexican populations. Australas. Plant Pathol. 39:217-225.

Dabek, A., and Waller, J. 1990. Black leaf streak and viral leaf streak: New banana diseases in East Africa. Int. J. Pest Manage. 36:157-158.

de Bellaire, L. D. L., Fouré, E., Abadie, C., and Carlier, J. 2010. Black leaf streak disease is challenging the banana industry. Fruits 65:327-342.

Drenth, A., Tas, I. C., and Govers, F. 1994. DNA fingerprinting uncovers a new sexually reproducing population of Phytophthora infestans in the Netherlands. Eur. J. Plant Pathol. 100:97-107.

Erima, R., Kubiriba, J., Komutunga, E., Nowakunda, K., Namanya, P., Seruga, R., and Tushemereirwe, W. K. 2017. Banana pests and diseases spread to higher altitudes due to increasing temperature over the last 20 years. Afr. J. Environ. Sci. Technol. 11:601-608.

Excoffier, L., and Lischer, H. E. 2010. Arlequin suite ver 3.5: a new series of programs to perform population genetics analyses under Linux and Windows. Mol. Ecol. Resour. 10:564-567.

Fahleson, J., Nakyanzi, M., Okori, P., Seal, S., Kenyon, L., and Dixelius, C. 2009. Genetic analysis of Mycosphaerella fijiensis in the Ugandan Lake Victoria region. Plant Pathol. 58:888-897.

Foure', E. 1987. Varietal reactions of bananas and plantains to black leaf streak disease. Pages110-113 in Banana and Plantain Breeding Strategies. G. J. Persley and E. A. De Langhe, eds. Proceedings of an International workshop held in Cairns, Australia, 13-17 October 1986. ACIAR Proceedings No. 21, ACIAR, Canberra, Australia.

Frossard, P. 1980. Apparition d'une nouvelle et grave maladie foliaire des bananiers et plantains au Gabon: la Maladie des raies noires: Mycosphaerella fijiensis Morelet. Fruits 35:519-527.

Fullerton, R., and Olsen, T. 1995. Pathogenic variability in Mycosphaerella fijiensis Morelet, cause of black Sigatoka in banana and plantain. N. Z. J. Crop Hortic. Sci. 23:39-48.

Garcia, S. A. L., van der Lee, T. A., Ferreira, C. F., Hekkert, B. T. L., Zapater, M. F., Goodwin, S. B., Guzmán, M., Kema, G. H. J., and Souza, M. T. 2010. Variable number of tandem repeat markers in the genome sequence of Mycosphaerella fijiensis, the causal agent of black leaf streak disease of banana (Musa spp). Genet. Mol. Res. 9:2207-2212.

Grognet, P., and Silar, P. 2015. Maintaining heterokaryosis in pseudohomothallic fungi. Commun. Integr. Biol. 8:e994382.

Grünwald, N. J., Everhart, S. E., Knaus, B. J., and Kamvar, Z. N. 2017 Best practices for population genetic analyses. Phytopathology 107: 1000-1010

Grünwald, N. J., Goodwin, S. B., Milgroom, M. G., and Fry, W. E. 2003. Analysis of genotypic diversity data for populations of microoganisms. Phytopathology 93:738-746.

Halkett, F., Simon, J. C., and Balloux, F. 2005. Tackling the population genetics of clonal and partially clonal organisms. Trends Ecol. Evol. 20:194-201.

Hayden, H. L., Carlier, J., and Aitken, E. A. B. 2003. Genetic structure of Mycosphaerella fijiensis populations from Australia, Papua New Guinea and the Pacific Islands. Plant Pathol. 52:703-712.

Hurlbert, S. H. 1971. The non-concept of species diversity: a critique and alternative parameters. Ecology 52:577-586.

Irish, B. M., Goenaga, R., Rios, C., Chavarria-Carvajal, J., and Ploetz, R. 2013. Evaluation of banana hybrids for tolerance to black leaf streak (Mycosphaerella fijiensis Morelet) in Puerto Rico. Crop Prot. 54:229-238.

Jombart, T. 2008. adegenet: A R package for the multivariate analysis of genetic markers. Bioinformatics 24:1403-1405.

Jombart, T., and Collins, C. 2015. A tutorial for Discriminant Analysis of Principal Components (DAPC) using adegenet 2.0.0. (Imperial College London), http://adegenet.r-forge.r-project.org/files/tutorial-dapc.pdf

Jombart, T., Devillard, S., and Balloux, F. 2010. Discriminant analysis of principal components: A new method for the analysis of genetically structured populations. BMC Genet. 11:94.

Kablan, L., Lagauche, A., Delvaux, B., and Legrève, A. 2012. Silicon reduces black Sigatoka development in banana. Plant Dis. 96:273-278.

Kamvar, Z. N., Tabima, J. F., and Grünwald, N. J. 2014. Poppr: An R package for genetic analysis of populations with clonal, partially clonal, and/or sexual reproduction. PeerJ 2:281.

Karamura, D. A., Karamura, E., and Tinzaara, W. 2012. Page121 in Banana Cultivar Names, Synonyms and Their Usage in East Africa. Bioversity International, Uganda.
Karaoglu, H., Lee, C. M. Y., and Meyer, W. 2005. Survey of simple sequence repeats in completed fungal genomes. Mol. Biol. Evol. 22:639-649.

Kimunye, J. N., Were, E., Mussa, F., Tazuba, A., Jomanga, K., Viljoen, A., Swennen, R., Muthoni, F. K., and Mahuku, G. 2020. Distribution of Pseudocercospora species causing Sigatoka leaf diseases of banana in Uganda and Tanzania. Plant Pathol. 69:50-59.

Leiva-Mora, M., Alvarado-Capó, Y., Acosta-Suárez, M., Cruz-Martín, M., Sánchez, C., and Roque-Morales, B. 2008. Enhanced sporulation, morphological and pathogenic characterization of Mycosphaerella fijiensis, causal agent of Musa Black leaf streak. Cent. Agríc. 35:33-39.

Ludwig, J., and Reynolds, J. 1988. Page 311 in Statistical Ecology. A Primer on Methods and Computing. John Wiley and Sons, New York, NY.

Mahuku, G. S. 2004. A simple extraction method suitable for PCR-based analysis of plant, fungal, and bacterial DNA. Plant Mol. Biol. Report. 22: 71-81.

Manzo-Sánchez, G., Orozco-Santos, M., Islas-Flores, I., Martínez-Bolaños, L., Guzmán-González, S., Leopardi-Verde, C. L., and Canto-Canché, B. 2019. Genetic variability of Pseudocercospora fijiensis, the black Sigatoka pathogen of banana (Musa spp.) in Mexico. Plant Pathol. 68:513-522.

Marín, D. H., Romero, R. A., Guzmán, M., and Sutton, T. B. 2003. Black Sigatoka: an increasing threat to banana cultivation. Plant Dis. 87:208-222.

McDonald, B. A. 1997. The population genetics of fungi: tools and techniques. Phytopathology 87:448-453.

McDonald, B. A., and Linde, C. 2002. Pathogen population genetics, evolutionary potential, and durable resistance. Annu. Rev. Phytopathol. 40:349-379.

McDonald, B. A., and Mundt, C. C. 2016. How knowledge of pathogen population biology informs management of Septoria tritici blotch. Phytopathology 106:948-955.

Milgroom, M. G. 1996. Recombination and the multilocus structure of fungal populations. Annu. Rev. Phytopathol. 34:457-477.

Milgroom, M. G. 2015. Population Biology of Plant Pathogens: Genetics, Ecology and Evolution. Page399. American Phytopathological Society Press, St. Paul, MN.

Mobambo, K. N., Gauhl, F., Vuylsteke, D., Ortiz, R., Pasberg-Gauhl, C., and Swennen, R. 1993. Yield loss in plantain from black Sigatoka leaf spot and field performance of resistant hybrids. Field Crops Res. 35:35-42.

Mouliom-Pefoura, A. 1999. First observation of the breakdown of high resistance in Yangambi km 5 (Musa sp.) to the black leaf streak disease in Cameroon. Plant Dis. 83:78.

Nei, M. 1978. Estimation of average heterozygosity and genetic distance from a small number of individuals. Genetics 89:583-590.

Neu, C., Kaemmer, D., Kahl, G., Fischer, D., and Weising, K. 1999. Polymorphic microsatellite markers for banana pathogen Mycosphaerella fijiensis. Mol. Ecol. 8:523-525.

Pasberg-Gauhl, C., Gauhl, F., and Jones, D. R. 2000. Black leaf streak: distribution and economical importance. Pages 37-44 in Diseases of Banana, Abaca and Enset. D. R. Jones, ed. CAB International, Wallingford, U.K.

Peakall, R., and Smouse, P. E. 2012. GenAlEx 6.5: genetic analysis in Excel. Population genetic software for teaching and research-an update. Bioinformatics 28:2537-2539.

Ploetz, R. C. 2001. Black Sigatoka of banana: The most important disease of a most important fruit. The Plant Health Instructor. doi:

Queiroz, C. B., Miranda, E. C., Hanada, E., Sousa, N. R., Gasparotto, L., Soares, M. A., and Silva, G. F. 2013. Distribution of mating-type alleles and M13 PCR markers in the black leaf spot fungus Mycosphaerella fijiensis of bananas in Brazil. Genet. Mol. Res. 12:443-452.

R Core Team. 2018. R: A language and environment for statistical computing. R Foundation for Statistical Computing, Vienna. https://www.R-project.org

Rivas, G. G., Zapater, M. F., Abadie, C., and Carlier, J. 2004. Founder effects and stochastic dispersal at the continental scale of the fungal pathogen of bananas Mycosphaerella fijiensis. Mol. Ecol. 13:471-482.

Robert, S., Ravigné, V., Zapater, M. F., Abadie, C., and Carlier, J. 2012. Contrasting introduction scenarios among continents in the worldwide invasion of the banana fungal pathogen Mycosphaerella fijiensis. Mol. Ecol. 21:1098-1114.

Robert, S., Rieux, A., Argout, X., Carlier, J., and Zapater, M. F. 2010. Optimized genotyping with microsatellite markers in the fungal banana pathogen Mycosphaerella fijiensis (Mycosphaerellaceae). Am. J. Bot. 97: $130-132$

Saville, A., Charles, M., Chavan, S., Muñoz, M., Gómez-Alpizar, L., and Ristaino, J. B. 2017. Population structure of Pseudocercospora fijiensis in Costa Rica reveals shared haplotype diversity with Southeast Asian populations. Phytopathology 107:1541-1548.

Shannon, C. E. 2001. A mathematical theory of communication. Mob. Comput. Commun. Rev. 5:3-55.

Simpson, E. 1949. Measurement of diversity. Nature 163:688.

Stoddart, J. A., and Taylor, J. F. 1988. Genotypic diversity: estimation and prediction in samples. Genetics 118:705-711.

Stover, R. H. 1976. Distribution and cultural characteristics of the pathogens causing banana leaf spot. Trop. Agric. 53:111-114. 
Tenkouano, A., Pillay, M., and Ortiz, R. 2011. Breeding techniques. Pages 181-202 in: Banana Breeding Progress and Challenges. M. Pillay and A. Tenkouano, eds. CRC Press, Boca Raton, FL.

Turgeon, B. G., and Yoder, O. C. 2000. Proposed nomenclature for mating type genes of filamentous ascomycetes. Fungal Genet. Biol. 31:1-5.

Zandjanakou-Tachin, M., Ojiambo, P. S., Vroh-Bi, I., Tenkouano, A., Gumedzoe, Y. M., and Bandyopadhyay, R. 2012. Pathogenic variation of Mycosphaerella species infecting banana and plantain in Nigeria. Plant Pathol. 62:298-308.

Zandjanakou-Tachin, M., Vroh-Bi, I., Ojiambo, P., Tenkouano, A., Gumedzoe, Y., and Bandyopadhyay, R. 2009. Identification and genetic diversity of Mycosphaerella species on banana and plantain in Nigeria. Plant Pathol. 58:536-546.
Zapater, M. F., Duchemin, M., Dussart, J., Coste, D., Brottier, P., and Carlier, J. 2008. Microsatellite markers for the fungal banana pathogens Mycosphaerella fijiensis, Mycosphaerella musicola and Mycosphaerella eumusae. Mol. Ecol. Resour. 8:1121-1125.

Zhan, J., Kema, G. H., Waalwijk, C., and McDonald, B. A. 2002. Distribution of mating type alleles in the wheat pathogen Mycosphaerella graminicola over spatial scales from lesions to continents. Fungal Genet. Biol. 36: 128-136.

Zhan, J., Torriani, S. F., and McDonald, B. A. 2007. Significant difference in pathogenicity between MAT1-1 and MAT1-2 isolates in the wheat pathogen Mycosphaerella graminicola. Fungal Genet. Biol. 44:339-346. 